\title{
A DISCRETE MODEL OF DEGREE CONCEPT IN NATURAL LANGUAGE
}

\author{
Shin-ichiro KAMEI and Kazmnori MURAKI \\ Information Technology Research Laboratories, NEC Corporation \\ 4-1-1, Miyazaki, Miyamae-ku, Kawasaki, 216 JAPAN \\ kamei@hum.cl.nec.co.jp, k-muraki@hum.cl.nec.co.jp
}

\begin{abstract}
Degree words in matural langunge, such as 'often' and 'sometimes,' do not have denotations in the real world. This canses some interesting characteristies for degree words. For example, the correspondence between the Finglish word 'often' and the intuitively corresponding Japanese worch is not obvions. This paper proposes a conceptual representation to describe a wide range of linguistic phenomena which aro rolated to degree concepts in natural language.
\end{abstract}

\section{Introduction}

Degree words in natural language, which are exemplifiod by the following, exist across parts of spechl and across specific languages.

(1) a. quantificrs: all, many, some, few, no b. advorbs: always, often, sometines, seldom, never c. adjectives: tall, short

Degree words have some interesting characteristics. First, quantities in the real world which can be represented by degree words vary pragmatically, depending on speakers, situations, etc. (Fanconnicr, 1975). 'This moans that degree words do not have denotations in the real world. Iowever, many degree expressions are used in claily life and it is not felt that they are particularly incomprohensible. The authors do not think that to moderstand the meanings of degree words is to uncherstand the real quantitics in the real workl.

Second, it is difficult to compare degree words in different languages. In the case of the English non-degree word ' $\mathrm{log}$,' we may think that the word semantically corresponds to the Japanese word 'inu' because these two words refer to the same object 'dog' in the real workl. However, this correspondence is not true of degree, words. The Linglish word 'often' intuitively corresponds to the Japanese word 'shibashiba,' but this correspondence is not obvious. 'Tlat is because these words do not have denotations in the real world.
These characteristics are related to the base of $\mathrm{Ma}^{-}$ chine Translation and its dictionaries. Even when the roal quantity, which is referred to by a degree word in a text, is not cloarly understood, it is usually believed that it is possible to translate the word into another language. When building bi-lingual dictionaries, it is necessary to consider the correspondence between degree words in each language. $\Lambda$ new reference framework is nceded by which to investigate to what extent the two words correspond to each other. These issues are also related to conceptual descriptions in large scale knowledge base projects, which have started recently.

Third, degree words have some characteristics which are independent from parts of speech. One of the phenomena degree words have in common is modification restrictions between degree words and degree intensifiers. Each degroe word has its own modification restriction (Bolinger, 1972; Quirk, 1985; Kamei, 1988, 1990). For exanple, 'all' and 'no' can be modified by 'almost,' but 'tall,' 'short,' 'many,' and 'few' cannot usually be so handled. On the other hand, 'tall,' 'short,' 'many,' and 'fow' can be modified by 'very,' but 'all' and '110' cannot. 'Some' and 'sometimes' cannot be modified by either 'very' or 'almost.'

Previous researchers pointed out a lot of important linguistic phenomena which are related to degree words but the issues described above were left uninvestigated. Barwise and Cooper (1981) investigate relations be tween determiners in Inglish and generalized quantifiers in logic. However, they did not focus so much on degree words, such as adjectives and adverbs in general. It is still undetermined how to fully comprehend such words as 'many' and 'a few.' Gazdar (1979) and rirschberg (1985) introduced idcas of a linear ordering of degree words and treated a wide range of phenomena related to degree words. However, they directly hanclled real words and treated 'positive words' such as 'all' and 'many', and 'negative words' such as 'few' and 'no' separately. Relations between the positive and negative words were not clear. In order to comprehend those unsolved linguistic phenomena, the authors propose a semantic morlel of degree concepts. 


\section{Discrete Degree Primitives and a List Expression}

'This section introduces discrete degree primitives and a list expression to represent meanings of degree concepts. From the perspective of quantities in the real world, 'many' and 'some' are similar. However, The modification restriction between degree words and degree intensifier shows that each word is normally modified by intensifiers selectively. This suggests the existence of DISCRETE degree concept primitives, which are independent from parts of specch. The authors introduce five basic semantic primitives ('A,' 'M,' 'S ,' ' $F$,' and ' $N$ ') indicating degree that are abstracted from the meanings of 'all,' 'many,' 'some,' 'few,' and 'no.' A list of degree primitives is used to describe meanings of degree words in terms of relative positions in the list expression.

$$
\text { (2) }\{\mathrm{A}, \mathrm{M}, \mathrm{S}, \mathrm{F}, \mathrm{N}\}
$$

The list expression above is a basic list of the discrete model. The authors divide meanings of degree words into two parts. For example, 'tall' and 'short' can be divided into the scmantic axis regarding 'tallness' and the degree concepts 'many (much)' and 'fow (little).' Tables 2 and 3 represent the latiter part of meanings of degree words. In these lists, '--' means that the value in that particular position is lacking.

Table 1: List Examples (1)

\begin{tabular}{|c|c|c|c|c|c|}
\hline Basic list & $\{A$, & $\mathrm{M}$ & $\mathrm{S}$ & $\mathrm{F}$, & $\overline{N\}}$ \\
\hline all, always & $\{\mathrm{A}$, & - & - & - & -3 \\
\hline many, often & $\{-$, & $\mathrm{M}$ & - , & - & $-\cdots$ \\
\hline some, sometimes & $\{-$ & - & $\mathrm{S}$, & $-;$ & $-\}$ \\
\hline few, scldom & $\{\cdots$, & - & - & $F$ & $-\}$ \\
\hline no, nover & $\{-$, & - & $-\cdots$, & - & $N\}$ \\
\hline
\end{tabular}

Table 2: List Examples (2)

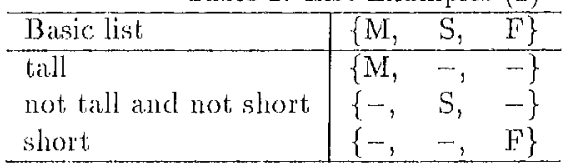

'The authors think that degres words are identified by their relative positions in the list expression. Tt is true that quantities in the roal world, which are expressed by degree words, are continuous. However, the authors think that language treats clegree concepts in a discrete way. 'Table 3 shows modification restrictions on degree intensifices using the primitives. In this table, 't' shows that the intensifiers can modify the degreo primitives, and "-' shows the intensifiers cannot modify the primitives. Note that these primitives are not real words and that they consistently describe relationships that are independent from parts of speech. These are important differences between this model and previous research reports.

Table 3: Modification Restriction of Degree Primitives and Intensifiers

\begin{tabular}{|l|l|c|c|c|c|c|}
\hline & & \multicolumn{5}{|c|}{ Degree Primitives } \\
\cline { 4 - 7 } Intensifiers & \multicolumn{1}{|c|}{ Examples } & A & M & S & F & N \\
\hline Booster & very, extremely & - & + & - & + & - \\
Compromiser & pretty, somewhiat & - & + & - & + & - \\
Iiminisher & a little, slightly & - & + & - & + & - \\
Approximator & almost, nearly & + & - & - & - & + \\
Maximizer & absolutely & + & - & - & - & + \\
\hline
\end{tabular}

\section{A Dual List Expression of De- gree Concept}

It is pointed out that degree words convey non-literal 'conversational' meanings when they are used. The difference between a literal meaning and a conversational meaning is called 'Conversational Implicature' (Grice, 1967). This section explains how this model treats this aspect of degree concepts.

\subsection{Question and Answer}

To exemplify Conversational Implicature, let us consider the following sentence, which includes a number.

\section{(3) I solved three of the problems.}

A natural interpretation of this sentence is "I solved just three of the problems, not all or four or two or one or none of them." However, in a logical way, this statement is true, when "I solved FOUR of them." For example, if the border line between success and failure of a test is three, this sentence is naturally spoken, even when, in fact, the person solved four of the problems (Chomsky, 1972; Ota, 1980; Ikeuchi, 1985). The following is a Yes/No question corresponding to sentence (3) and its answers. Interestingly, both of the answers below are possible in this case.

(4) A: Did you solve three of the problems?

$\begin{aligned} \text { B: } & \text { - Yes, in fact I solved four. } \\ & \text { - No, I solved four. }\end{aligned}$

In order to handle these plienomena, more complex states than just 'three' for the moaning of the number three are needed. The authors think that five states are actually needed for clarity: (1) All problems are solved. (2) The number of solved problems exceeds the number which appears in the sentence (=three in this case). (3) The number of solved problems is exactly the number which appears. (4) The number of 
solved problens docs not total the number which appears. (5) No problens are solved. 'The anthors introduce the five prinitives, ' $\Lambda$, '>n1,' $:=11$, ' $<\mathrm{n}$,' and ' $\mathrm{N}$ ', corresponding to these five states, respectively. A list expression is introduced as follows.

$$
\text { (5) }\{\mathrm{A},>n,=\mathrm{n},<\mathrm{n}, \mathrm{N}\}
$$

The five states are represented with relative positions shown in trable 4.

\begin{tabular}{|c|c|c|c|c|c|}
\hline \multicolumn{6}{|c|}{ Table 4: Tist lixamples (3) } \\
\hline all & $\{A$, & $\cdots$ & $\cdots$ & , & $-\}$ \\
\hline$>$ three & $\{-$, & $>\mathrm{n}$ & -- & $\therefore$, & $-\}$ \\
\hline three & $\{-$, & $\cdots$ & $=\mathrm{n}$, & $\cdots$ & $-\}$ \\
\hline$<$ three & $\{\cdots$, & - & $\cdots$ & $<n$ & $-\cdot\}$ \\
\hline none: & & - & & $\cdots$ & N) \\
\hline
\end{tabular}

To express the Conversational Implicature, the anthors represent the meaning of the number part in sentrence (3) with a chal hist.

$$
\left\{\begin{array}{l}
-,-\cdots n,-,-, \\
A,>11,=11,-\cdots,-
\end{array}\right\}
$$

The upper row (the direct meaning row) in this representation shows the state whercin the number of solved problems is tho number that appears in sentence (3). The lower row (the possible interpretation row) expresses the possible numbers of solved problems, when sentence (3) is apoken. For exumple, this statement is false, when "T solved TWO of then." hogically, however, this statoment is TRUE, when "I solved FOUR of them." "I'lue dual list represents the first phenonenon. The diflerence between the two sows, 'A' and ' $>$ u' in this casie, cxpresses the possibilities of Conversational Tmplicature. When this sentence is sjoken, the clegree part of this sentence conveys the meanings which correspond to BOrlt of the rows in the dual list. 'That is, it uot only is indicated by the upper 'direct' row, but also by the lower 'possible' row.

Tu an affirmative sentence, the upper 'direct' neaming may be dominant. Howewer, in the ease of an interrogative sentence, the lower 'possible' meaning plays a more important role. This model explains the two posssible anls;wers in utticrance (1) in a sinnple way. In Fig. 1 , the meaning of the gutestion is expressed with a dual list. The mening of the real situation (the meaning of 'four' in this case) is expressed with a single list (in the middle), because it is not an intorpretation, but is a situation. Whon comparing the npper row of the question and the row expressing, tho situation 'four, there is no connenon value. 'Ihere is no intersection between then. 'This case corresponds to the answer with 'No.' When comparing the lower 'possible' row and the situation, there is an intersection, that is, the value ' $>11$.'
'Therefore the answer is 'Yes.' 'This intersection operation is a simple and natural way to calculate possible answers to a question which includes a number.

$$
\begin{aligned}
& \text { Question (' } 3 \text { '?) } \quad \text { Situation (' } 4 \text { ') Answers } \\
& \left\{\begin{array}{l}
-,-, \cdots n,-,- \\
A,>n,--11,-,-\cdots
\end{array}\right\}-\{-,>n,-,-,-,\} \longrightarrow \text { NO }
\end{aligned}
$$

Figure 1: Intersection Operation for $Q$ and $\mathrm{A}$

\subsection{Negation Operations}

This section introduces Negation Operations, which are defined on the dual list representation. Sentence (7) is a negative sentence which corresponds to sentence (3). A negative sentence like this has several interpretations which previous research has pointed out but has not been able to treat satisfactorily. This moclel calculates all the possible interpretations of a negative sentence from the representation of the original affirmative sentence.

(7) I didn't solve throe of the problems.

One possible interpretation of sentence (7) is that there are thee problems that "I did not solve" (Interpretation A). In this interpretation, the number 'three' is not under the influence of the negation; the number is ont of the scope of negation. 'To obtain this interpretation, it is not necessary to change the dual list for the original affirmative sentence (0). It is necessary to change the meaning of the values from the number of the solved problems to the number of unsolved problems in the representation of the original affirmative sentence (Fig. 2). The lower row expresses the possibility that the number of the unsolved problems exceeds three.

$$
\begin{aligned}
& \text { Affirmative Negative } \\
& \left\{\begin{array}{l}
\cdots,-,:=n,-,- \\
\Lambda,>11,=\mathrm{n},--,
\end{array}\right\} \longrightarrow\left\{\begin{array}{l}
-,-,=11,-,- \\
A,>11,=\mathrm{n},-,-
\end{array}\right\} \\
& \text { Solved problems Unsolved problems } \\
& \text { linterpretation (A) }
\end{aligned}
$$

Figure 2: One Negative Interpretaion from Affirnative Dual List

Where the number ( $=$ thee in this case) is within the scope of negation, the negative sentence requires other interpretations. 
(8) A: Did you solvo three of the problems?

B: No, I didn't (get to) solve tluree of the probloms.

$$
\text { -.....- Interpretation (B) }
$$

Response B might moan that some of the problems were solved, but that the number did not reach three. This interpretation can be obtained from the model shown in Fig. 3, and the negation operation is shown in Table 5.

$$
\begin{aligned}
& \text { Affirmative } \\
& \left\{\begin{array}{r}
-,-,=n,-,- \\
A,>n,=n,-,-
\end{array}\right\} \\
& \text { (1) Reverse each row } \\
& \{A,>11,-,<n, N\} \\
& \{-,-,-,<\mathrm{n}, \mathrm{N}\}
\end{aligned}
$$

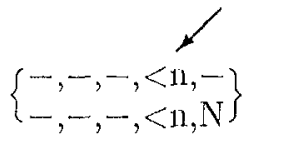

Figure 3: Two Negative Interpretations from Affirmative Dual List

1. Reverse cach affirmative row.

2. Select the COMMON part of the two rows.

The result is a new possible interpretation row.

3. Omit the edge values ( $A$ and $N$ ).

The result is a new direct meaning row.

Table 5: Negation Operation for Interpretation B

Step 1 in Table 5 realizes a primitive negation operation on each row. This interpretation of the negative sentence is consistent with the negations of both the direct meaning and the possible implication. Step 2 realizes this condition. This interpretation usually implies that there aro sone solved problems. This means the negation usually does not deny the existence of the solved problems. However, in a logical way, no problem being solved is a possible situation. Step 3 realizes this condition.

(9) A: Dicl you solve three of the problems?

C: No, I didn't solve THREE of the problems: I solved ALL of them.

$$
\text { -...-- Interpretation (C) }
$$

The above is a possible utterance, which requires another interpretation. Table 6 shows the way to calculate this interpretation (Interpretation (C)).
1. Reverse each affirmative row.

2. Select the DIFFEREN'T part of the two rows. The result is a new possible interpretation row.

3. Omit the edge values (A and N).

The result is a now direct meaning row.

Table 6: Negation Operation for Interpretation C

This interpretation differs from interpretation $\mathrm{B}$, only at Step 2, that is, 'to select the DIFFERENT part of the two rows.' This means that the interpretation is consistent with only the negation of the direct meaning, and does not satisfy the negation of the possible implication. Step 2 realizes this condition. This exemplifies that the Conversational Implicature can be canceled. In speech, stress is put on THREE and ALL in this interpretation, and this linguistic phenomenon is accounted for in Step 2.

\section{Negation of Degree Expres- sions in Natural Language}

In this section, the dual list representation and the operations introduced in the previous section are applied to degree words other than numbers.

\section{1 'All,' 'no,' 'some,' and 'not all'}

Here, we will apply the same model to the relations between 'all,' 'some, 'no,' and 'not all' in natural language. Sentence (10-1) logically entails sentence (10$2)$. Sentence (10-2) usually implies sentence (10-3). However, sentence (10-3) contradicts the original sentence (10-1). A carcless mixture of logical implication and usual implication in language makes the inference of (10-3) from (10-1) unreasonable (Horn, 1972; Ota, 1980; McCawley 1981).

(10-1) All students are intelligent.

(10-2) Some students are intelligent.

(10-3) Some students are NOT intelligent.

The discrete model is a useful tool for describing these relations. List (11) is used to express relations between 'all,' 'some,' 'no,' and 'not all $(=$ some ... not).' In this case, only three primitives are used.

$$
\text { (11) }\{\mathrm{A}, \mathrm{S}, \mathrm{N}\}
$$

In this list, the value ' $\mathrm{S}$ ' corresponds to the state wherein there are SOME students who are intelligent and SOME other students who are NOT intelligent. The meanings of these words are also expressed with a dual list. Figure 7 graphically represents this. 


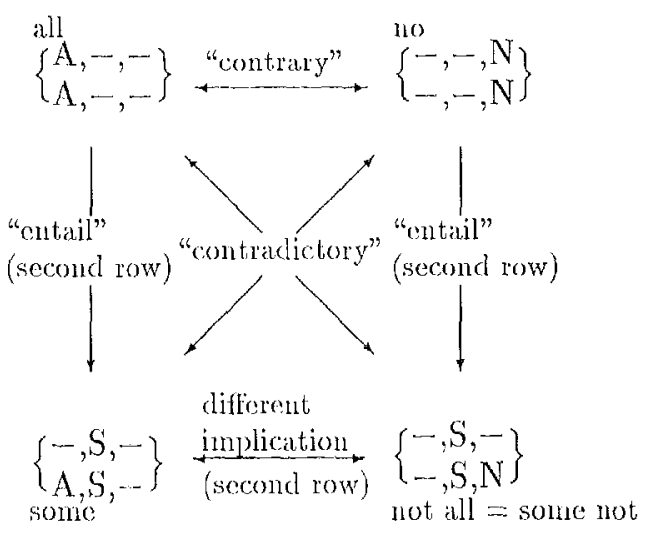

Fignee 4: 'All,' 'some,' 'no,' and 'not all'

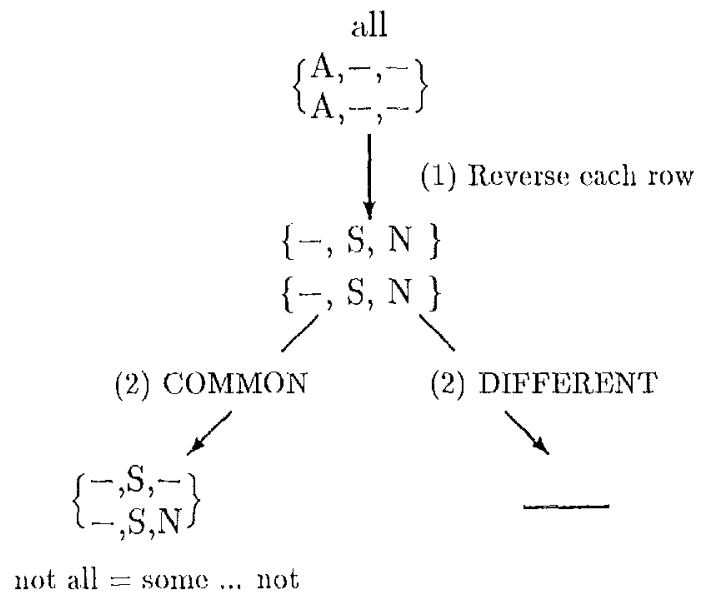

Figure 5: Negation Operation executed on 'ALL'

\section{2 'Not many' and 'not a few'}

'This section represents neanings 'many,' 'a few,' and 'few', and applies the negation operations on these concepts. Fignre 6 shows dual list representations for these three concepts. This figure shows that the cliference between 'fow' and 'a few' is in the lowor possible moaning row. It is the first time that the difference between the two is explicitly shown.
(a) many $\quad\left\{\begin{array}{l}-M,-,-,-- \\ A, M,-\cdots,--,\end{array}\right\}$
(b) a few $\quad\left\{\begin{array}{l}-,-,-, F,-\cdots \\ A, M, S, F,-\end{array}\right\}$
(c) fow$$
\left\{\begin{array}{l}
-,-,-, \mathrm{F},- \\
-,-,-, \mathrm{F}, \mathrm{N}
\end{array}\right\}
$$

of negation, Table 5 , used for numbers will also obtain the representation of 'uot all' from that of 'all' in Fig. 4. The other negation operation, Table 6, produces nothing in this case ( $F$ ig. 5). The negation operations a.re basic and genoral.

Note that " $\mathrm{S}$ ' in list (11) in this section montions only the cxistence of intelligent studentis and non-intelligent students. In Section 2, the same symbol 'S' was used for the meaning of 'some' which is relatively defined in the $\{A, M, S, F, N\}$ (list (2)). In that case, the value 'S' represents a quantitative aspect of 'some.' A relation between ' $S$ ' in list (11) and ' $S{ }^{+}$' = ' $S$ ' in list (2) is described as follows:

(12) $\mathrm{S} \rightarrow\left(\mathrm{M}, \mathrm{S}^{+}, \mathrm{F}\right)$

However, the authors used the same value 'S' in both listi; becanse the difference between these two 'S's is represented by the set of values in list expres. sions. These two 'S's correspond to anbiguities which the word 'some' in natural language has. 
many

$$
\begin{aligned}
& \left\{\begin{array}{l}
-, M,-,-,-\cdots \\
A, M,-,-,
\end{array}\right\} \\
& \text { (1) Reverse each row } \\
& \{\mathrm{A},-\mathrm{S}, \mathrm{F}, \mathrm{N}\} \\
& \{-,-, \mathrm{S}, \mathrm{F}, \mathrm{N}\}
\end{aligned}
$$

(2) COMMON

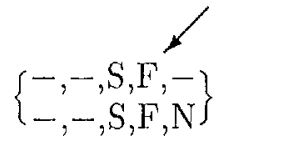

Usual interpretation
(2) DIFFERENT

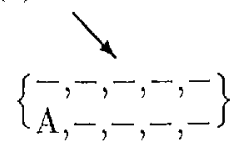

Unusual interpretation
Figure 7: Not many

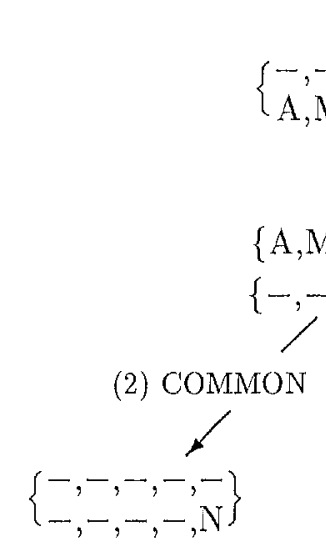

Unusual interpretation a few

$\left.\begin{array}{l}-,-,-F,-- \\ A, M, S, F,-\end{array}\right\}$

(1) Reverse eacli row

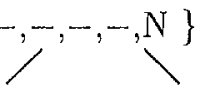

\section{(2) DIFFERENT

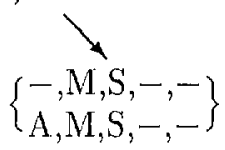

Usual interpretation

Fignue 8: Not a few

This paper introduced eight basic degree primitives for degree concept, that is, 'A,' 'M,' $S$,' ' $F$,' $N$,' ' $>n$,' '=n,' and '<n.' However, the authors do not claim that these eight primitives are sufficient to indicate all degree concepts. Instead, the authors claim that people comprehend degree concepts in a discrete way, and that degree concepts are identified by their relative positions in the framework of understanding. Consider the following examples concerning another degree concept 'several,' which differs from these cight degree concepts.

\section{(13) They legally have several wives.}

Quantitics, which are refored to by 'several' and 'a few,' seem to be close. It is often said that quantities referred to by 'several' include five or six, and more than the quantities refered to by 'a few.' However, sentence (13) shows that 'several' means more than one in this case. Previous researchers have not been successful in describing the difference between 'several' and 'a few.' The authors think that 'several' should be in a list including 'several' and 'one,' while 'a few' should be in a list which contains 'a few' and 'many.' 'Several' implies 'not one,' while 'a few' implies 'not many.' An important point is that the difference between 'several' and 'a few' is not the exact quantity involved, but a framework of understanding, that is, the set of values in the lists and their relative positions.

\section{3 'OR' in Natural Language and Negation}

It has been shown that the logical operator 'OR' has characteristics similar to degree concepts (Gazdar, 1979). This is because 'or' in natural language generally has two interpretations, the 'inclusive or' and the 'exclusive or.' This section applies the same model for degree concepts to a logical opcrator 'OR' and 'or' in natural language.

It is difficult to conceptnalize the negation of 'or' in natural language, in a usual sense, although negation of 'and' is easy. Logically, however, the negation of the logical operation 'OR' (that is, 'Inclusive or') is 'NOR.' However, in a sense in natural language, 'AND' instead of 'NOR' can also be a negation of 'OR.'

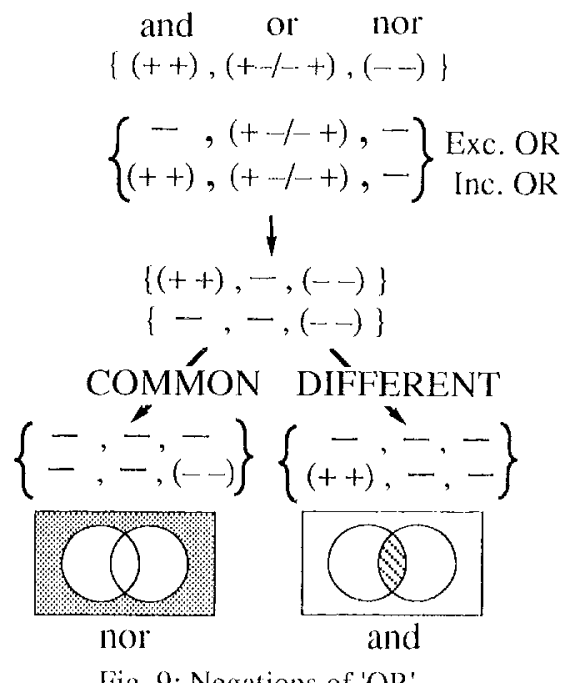

Fig. 9: Negations of 'OR'

Figure 9 shows the relationship betweon the inclusive and exclusive 'or' and their negations. The authors use three states: $(++),(+-/-+)$, and $(--)$. 'Exclusive $o r$ ' is a direct meaning of 'or' and 'inclusive or' is a possible interpretation of 'or' in this framework. The same negation operations will produce the two nega- 
tioms of 'or', that is, both NOR and AND. The direct meaning rows in the two interpretations of negations of 'or' have no ralues. This corresponds to the fact that it is difficult to consider the negation of 'or' in natural language. Note that the dual list for 'or' and the chal list for 'some' in Fig. 4 have an iclentical structure. It is equally explained that the negation of 'some' is difficult to consider in natural language, while the negation of 'all' is easy.

\section{Conclusion}

T'his paper has prosenterl a new nodel for degree concepts in natural language. The chancteristics for the model are: (1) The discreto degree primitives. (2) The list representation of degree concepts. (3) The dual list representation for possibilities of Conversational Implicature. (4) The intersection operation on the list for realizing entrailment of two concepts. (5) The negation operations on the dual list to calculate all the possible interpretations of negation of degrec concepts.

The model describes, calculates, aur explains a wide range of linguistic phenomena related to degrec comcopts, such as (1) Modification Restrictions between degree intensifiers and degree words across parts of sperch. (2) All the possible answers to a question which contains a cluantitative worel. (3) All the possible interperations of negation of quantitative words. (4) The difference betwen 'fow' and 'a fow.' (5) The vagucness of euphentibn of negations of degres words, such as 'not many' and 'nest a few.' (6) 'The difficulty of applying negation for some duantitative words, such as 'some' and 'or.'

People use a lot of degree words and communicate with each other in daily life, even when guantities which are expressed by then may not be precisely understood. 'Lhe anthors herefore think that natural language in itself has a DISCREJT tramework of degree concept, and that both the speaker and the hearer must have a conmon frane of understanding, before? holding a specific converiatiou. To nuderstand degree concents is to moderstanel their relative positions in a discrete frame of understianding. 'This is the anthors' viewpoint on degree coneent communication.

The correspondence between the Jinglish word 'often' and the Japranewe word 'slibashliba' has been established and is gencrally conceded as being appropriate. However, that is not just because these two words refor to the same real quantity. What is common betwon the two is relative position in the multi-window clevice. That establishes the correspondence for the mennings of the two.

This noded also dencribos phenonona related to
'OR' in logic and 'or' in natural language. This suggests that the model represents substantial structures in natural language and is a suitable tool for natural language understanding. The authors hope that this model will be one of the possible extensions of the firstorder Logic.

\section{Acknowledgments}

I'he authors wish to express appreciation to the late Stephen Cudhea, NEC Conporation, whose classification of thiglish adverbs made this research possible. The numerous research data were obtained during one of tho authors' stay at Computing Research Laboratory (CRR), New Mexico State University. The authors thank Yorick Wilks, who was Director of CRL, Takahiro Wakao, David Farwell, John Barnden, and Stephen Helmreich at CRL for their suggestions.

\section{References}

[1] Bar'wise, J. and ]k. Cooper (1981). 'Generalized quantifiers and natural language." Language and Philosophy 4.2, pp. 159-219.

[2] Bolinger, D. T. (1972). Degree words. Monton.

[3] Chomsky, N. (1972). Studies on semantics in generative grammat. Mouton.

[4] Fauconnier, G. R. (1975). 'Pragmatic scales and logical structure.' linguistic Inquiry 6 , pp. 357-375.

[5] Gavdar, G. (1979). Pregmalics; Implicalure, Presupposilion, and Logical f'orm. Academic l'ress.

[6] Girice, II. l'. (1975). 'Togic: and conversation' In P. Cole and J. J. Morgan Wds., Speech acts, pp. 45-58. Syntax and Semantics 3. Acadenic l'ress.

(7) Ifirschberg, J. 13. (1985). 'A Theory of Scalar Implicature' Plh. 1). dissertation, University of Pennsylvania.

[8] Iforn, L. R. (1972). 'On the semantic properties of logical operators in English' Reproduced by the Indiana University linguistics (Jul (1976).

[9] Ikeuchi, M. (1985). Meishi-hu no yentei hyougen (Noun phrase specifying e:zpressions), (in Japanese). 'laishukati.

[10] Kamei, S. and K. Muraki (1988). On a Model of Degree Fxpression, (in Japanese). NI,C 88-6. The Institnte of blectronics, Information and Communication Engineers.

(11) Kamei, S., A. Okumura, and K. Muraki (1990). Syntax of Finglish Adverb), (in Jipanese). Proceeding of the 10th Confercuce of Information Processing Society of Japan, Vol 1, PP. 417-4.18.

[12] McCawley, J. D. (1981). Fueryllhing that linguists have Always Wanted to Know aboul loogic but were ashamed to ask. 'I'he University of Chicago Press.

[13] Ota, A. (1980) Hitei no Imi (Meanings of Negation), (in Japanese), Taishukan.

[14] Quirk, R., S. Greenbaum, G. Leech, and J. Svartvik. (1985). A Comprehensive Grammar of the Linglish Language. longman.

[15] Yagi, 'T'. (1987). 'T'eito hyougen to hikaku kouzou (Degree expressions and comparalive struclutes), (in Japanese). 'Taishukan. 